\title{
Induction of apoptosis by fucoidan isolated from a traditional food, Saccharina longissima, in U937 human leukemia cells
}

\section{Junpei Shimabukuro, ${ }^{1}$ Takuya Yogi, ${ }^{1}$ Mariko Nago, ${ }^{1}$ Takeshi Teruya, ${ }^{1}$ Teruko Konishi ${ }^{1}$ and Masakuni Tako ${ }^{1,2 *}$}

${ }^{1}$ Department of Subtropical Bioscience and Biotechnology, University of the Ryukyus, Nishihara, Okinawa 903-0213, Japan; ${ }^{2}$ Health and Longevity Research Laboratory, 2-3-22 Awawse, Okinawa, Okinawa 904-2172, Japan

*Corresponding author: Masakuni Tako, Department of Subtropical Bioscience and Biotechnology, University of the Ryukyus, Nishihara, Okinawa 903-0213, Japan

Submission Date: December 26 ${ }^{\text {th }}$, 2017, Acceptance Date: April 27 ${ }^{\text {th }}$, 2018, Publication Date: April $20^{\text {st }}, 2018$

Citation: Shimabukuro J., Yogi T., Nago M., Teruya T., Konishi T., Tako M., Induction of apoptosis by fucoidan isolated from a traditional food, Saccharina longissima, in U937 human leukemia cells. Functional Foods in Health and Disease 2018; 8(4): 242-255. DOI: https://doi.org/10.31989/ffhd.v8i4.411

\begin{abstract}
Background: A brown seaweed, Saccharina longissima (Laminaria angustata var. longissima) has been consumed in Okinawa for 300 years. It is native to the southernmost part of Japan, in Okinawa, but grows on the Pacific coast (Kushiro and Nemuro) in Hokkaido in the northernmost part of Japan. Previously, we reported the structural characteristics from S. longissima. The fucoidan consisted of L-fucose, D-galactose, D-glucose, D-xylose, D-glucuronic acid, and sulfuric acid. This fucoidan activated the RAW 264.7 murine macrophage cell line. The aim of this study was to investigate the effects of a fucoidan isolated from Saccharina longissima on cell antiproliferation and apoptosis in the U937 human leukemia monocyte lymphoma cell line.
\end{abstract}

Methods: U937 cells were incubated with four fucoidan concentrations. The degree of apoptosis 
was determined using the APOPercentage APOPtosis assay, caspaer-3 activity assay and Western blotting analysis assay.

Results: The treatment of cell with a fucoidan highly substituted with sulfate, in addition to Lfucose residues, inhibited cell growth. Apoptosis increased in U937 cells in a dose-dependent manner following the addition of fucoidan. However, the fucoidan did not induce apoptosis in the presence of caspase inhibitor (z-VAD-FMK).

Conclusion: The fucoidan from Saccharina longissima induced apoptosis in U937 cells. Accordingly, the kelp containing this fucoidan may contribute to the observed longevity of the Okinawan population.

Keywords: fucoidan, Saccharina longissimi, brown seaweed, traditional food, human leukemia cells, apoptosis

\section{INTRODUCTION}

A brown seaweed, Saccharina longissima (Laminaria angustata var. longissima) has been consumed in Okinawa for 300 years. It is native to the southernmost part of Japan, in Okinawa, but grows on the Pacific coast (Kushiro and Nemuro) in Hokkaido in the northernmost part of Japan. We previously reported the structural characteristics of a fucoidan from S. longissima. The fucoidan consisted of L-fucose, D-galactose, D-glucose, D-xylose, D-glucuronic acid, and sulfuric acid. The fucoidan was separated into four fractions by anion exchange chromatography. The chemical structure of the main fraction consisted of 1,3-linked $\alpha$-L-fucopyranosyl residues, substituted with sulfate groups at the C-4 position on the main chain, as shown in Figure 1 [1].

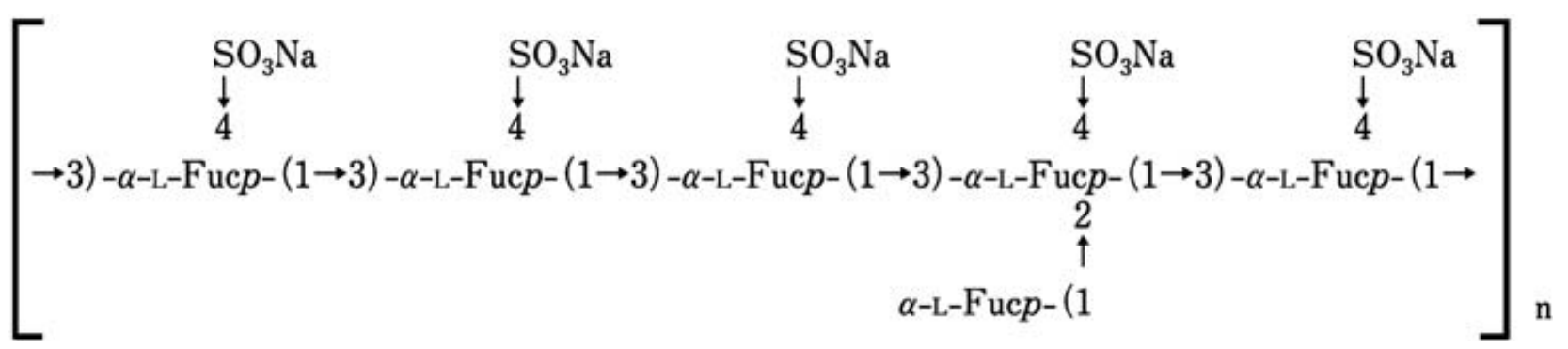

Figure 1. Chemical structure of the fucoidan from Saccharina longissima. 
There have been many reports on biological activities of fucoidan from many brown seaweeds on anti-coagulant [2], anti-virus [3,4], immune-enhancing [5,6], anti-tumor [7,8], and inducing apoptosis [9-17].

Apoptosis is characterized by cell morphology changes including blebbing, shrinkage and nuclear fragmentation that eventually leads to cell death. The apoptotic process plays critical roles in immunity and cancer, and its programming requires caspases mediators. Among the caspases, caspase-3 plays a particularly important role in apoptosis $[9,10$.$] .$

The aim of this study is to investigate the effects of a fucoidan isolated from Saccharina longissima on cell proliferation and apoptosis in the U937 human leukemia monocyte lymphoma cell line.

\section{MATERIALS AND METHODS}

\section{Materials}

RPMI1640 medium, D-PBS (Dulbecco's phosphate buffered saline), modified Eagle medium (DMEM), fetal bovine serum (FBS), penicillin, and streptomycin were purchased from Gibco BRL (Grand Island, NY, USA). The WST-8 cell-counting kit was obtained from Dojin Chemicals Laboratories (Kumamoto, Japan). The Pierce BCA Protein Assay Kit was from Thermo Scientific (Rockford, MD, USA). Anti-caspase-3 mouse antibody, horseradish peroxidase (HRP)-linked anti-rabbit IgG antibody, and pan caspase inhibitor (z-VAD-fmk) were from Cell Signaling Technology (Danvers, MA, USA). Reagents for enhanced chemical luminescence (ECL) and western blotting detection kit were obtained from Amersham Biosciences (Buckinghamshire, UK). The APOPercentage Apoptosis assay kit was from Biocolor Ltd. (Belfast, Northern Ireland). The CaspACE colorimetric assay system was from Promega Co. (Madison, WI, USA). All other chemicals were of analytical grade.

\section{Preparation of fucoidan}

Saccharina longissima was purchased from a local market in Naha City, Okinawa, Japan. The algae were washed with tap water, air dried at $40{ }^{\circ} \mathrm{C}$ for $48 \mathrm{~h}$, and ground into a powder.

A sample $(20 \mathrm{~g})$ of algal powder $(20 \mathrm{~g})$ was suspended in distilled water adjusted $\mathrm{pH}$ at 3.0 with $0.1 \mathrm{M} \mathrm{HCl}$ and stirred at $60{ }^{\circ} \mathrm{C}$ for $3 \mathrm{~h}$ to extract the fucoidan. The extract was filtered through Celite 545, the filtrate was neutralized with $0.1 \mathrm{M} \mathrm{NaOH}$, and the fucoidan was precipitated by the addition of two volumes of ethanol. The precipitate was dried in vacuo. The resulting crude fucoidan was dissolved in $0.1 \mathrm{M} \mathrm{CaCl}_{2}$ and passed through Celite 545, The filtrate was dialyzed 
against water for $24 \mathrm{~h}$, the dialysate was precipitated by addition of two volumes of ethanol and the precipitate was dried in vacuo. The resulting semi-purified fucoidan was redissolved in distilled water, 5\% cetylpyridinium chloride $(\mathrm{CPC})$ was added to precipitate the fucoidan, and the precipitate was dried in vacou. The fucoidan-CPC complex was dissolved in $3 \mathrm{M} \mathrm{NaCl}$ and precipitated with addition of two volumes of ethanol. The precipitate was dissolved in distilled water and dialyzed for 24 against distilled water. The resulting dialysate was passed through Celite 545 and lyophilized.

\section{Chemical procedures}

The total carbohydrate and uronic acid content were determined with the phenol-sulfuric acid [18] and carbazol-sulfuric acid [19] methods using L-rhamnose and D-glucuronic acid, respectively, as standards. The purified polysaccharide $(70 \mathrm{mg})$ was dissolved in distilled water $(20 \mathrm{~mL})$ and sulfuric acid was added to reach a final concentration of $1.0 \mathrm{M}$. The mixture was subsequently heated to $100^{\circ} \mathrm{C}$ for $3 \mathrm{~h}$. The resulting hydrolysate was neutralized with $\mathrm{BaCO}_{3}$.

\section{High-performance anion exchange chromatography coupled with a pulse amperometric detection (HPAEC-PAD)}

The monosaccharides in the polysaccharide hydrolysate were identified using a HPAEC system (DX-500, Dionex Co., CA, USA), fit with a Carbopack PA1 column and a pulsed amperometric detector. The column was eluted with $10 \mathrm{mM} \mathrm{NaOH}$ at flow rate of $1 \mathrm{~mL} / \mathrm{min}$ at $35^{\circ} \mathrm{C}$.

\section{Determination of the sulfate and uronic acid contents}

Purified polysaccharide (10 mg) was dissolved in distilled water and hydrochloric acid was added to reach a final concentration of $1.0 \mathrm{M}$. The mixture was heated at $110{ }^{\circ} \mathrm{C}$ for $3 \mathrm{~h}$. The hydrolysate was applied to the HPAEC system (DX-500, Dionex Co., CA, USA) equipped with an A-SC4 column equilibrated with $1.7 \mathrm{mM} \mathrm{NAHCO}+1.8 \mathrm{mM} \mathrm{NaCO}_{3}$. The chromatography was carried out at $35^{\circ} \mathrm{C}$ at a flow rate of $1.0 \mathrm{~cm} / \mathrm{min}$.

\section{Cell culture}

U937 cells (JCRB9301) were obtained from the Human Science Research Resources Bank, Tokyo, Japan. The cells were cultured in RPMI1640 medium containing 10\% v/v FBS, 100IU/mL 
penicillin, and $100 \mu \mathrm{g} / \mathrm{mL}$ streptomycin. The cells were plated and incubated at $37^{\circ} \mathrm{C}$ in a $5 \% \mathrm{CO}_{2}$ atmosphere [10].

\section{Anti-proliferative activity assay}

The anti-proliferative effect of the fucoidan was measured with the WST-8 method. U937 cells in exponential growth phase were suspended in triplicate in a 96-well microplate at a final concentration of $3 \times 10^{5}$ cells $/ \mathrm{mL}$ in RPMI1640 medium. The cells were then exposed to various concentrations of fucoidan for $48 \mathrm{~h}$. After cultivation, $10 \mu \mathrm{L}$ of WST-8 solution was added to each well and incubated again at $37^{\circ} \mathrm{C}$ for $3 \mathrm{~h}$. The optical density was measured at $620-450 \mathrm{~nm}$ in a microplate reader (Model 650, Bio-Rad Laboratories, USA). The anti-proliferative effect was expressed as the percentage of viable cells relative to an untreated control [10].

\section{Microscopy analysis}

U937 cells were plated in a $60 \mathrm{~mm}$ dish without or with $100 \mu \mathrm{g} / \mathrm{mL}$ fucoidan and incubated for 30 h. The cells were then imaged using a phase contrast microscope (ECLIPSE TS-100, Nikon, Japan) equipped with a digital camera (COOLPIX 4500, Nikon).

\section{Apoptosis assay}

The degree of apoptosis was determined using the APOPercentage Apoptosis assay. U937 cells in the exponential growth phase were suspended in a 24-well microplate at a final concentration of $1 \times 10^{5}$ cells/mL in RPMI1640 medium containing $2 \%$ FBS. The cells were incubated for $30 \mathrm{~h}$ in the presence or absence of $100 \mu \mathrm{g} / \mathrm{mL}$ fucoidan. After $24 \mathrm{~h}$ pre-incubation, various concentrations of fucoidan were added and the cells were cultured for a further $48 \mathrm{~h}$. A $12.5 \mu \mathrm{L}$ volume of APOPercentage dye solution was then added to each well and incubated at $37{ }^{\circ} \mathrm{C}$ for 30 min in a 24-well microplate. The cells were then washed with D-PBS, collected by centrifugation, and lysed by adding cell lysis solution $(0.1 \mathrm{M} \mathrm{NaOH})$. The optical density was measured at 550 nm using a microplate reader [10].

\section{Caspase-3 assay}

The caspase-3 activity was determined using a colorimetric CaspACE assay system following the manufacturer's protocol. U937cells were incubated without or with fucoidan and then collected and rinsed with ice-cold D-PBS and lysed on ice in cell lysis buffer. The protein concentration in the lysate was measured with a Pierce BCA Protein Assay Kit. The cell lysate was centrifuged 
$\left(13,200 \times g, 10 \mathrm{~min}, 4^{\circ} \mathrm{C}\right)$, then the supernatant was collected, and the assay buffer, DMSO, DTT, and Ac-DEVD-pNA (caspase-3 substrate) were added. Each sample was covered and incubated at $37{ }^{\circ} \mathrm{C}$ for $16 \mathrm{~h}$. The absorbance at $405 \mathrm{~nm}$ was measured with a microplate reader [10].

\section{Western blotting analysis}

Cells were cultured in a 100mm dish without or with fucoidan. The cells were washed with cold D-PBS and lysed with SDS sample buffer (62.5 mM Tris-HCl, 2\% SDS, $10 \%$ glycerol, and 10\% mercaptoethanol). Protein contents were determined with a DC Protein Assay Kit (Bio-Rad Laboratories, CA, U.S.A.) using bovine serum albumin as a standard. An aliquot of total protein was separated by SDS-PAGE and transferred to PVDF membrane (Merck Millipore, Concord RoadBillerica, MA, USA). The membrane was blocked at room temperature for $1 \mathrm{~h}$ with $0.1 \%$ Tween 20 in Tris-buffered saline containing 5\% skim milk. Western blotting was carried out using mouse primary antibody for anti-caspase-3 (1:2000) and then with horseradish peroxidase conjugated anti-rabbit IgG antibody by using an ECL Western blotting detection kit. Immunoreactive bands were visualized by chemiluminescence [10].

\section{Statistical analysis}

The experiments were carried out in triplicate and data were expressed as the mean \pm S.E.M. Data were analyzed by student's t test to evaluate the significance of differences with *:p<0.01 being regarded as statistically significant.

\section{RESULTS}

\section{Chemical components of fucoidan}

The yield of crude fucoidan was estimated as $8.7 \%$ based on the dried weigh of the algae. The fucoidan yield was reduced to $5.5 \%$ after purification. The fucoidan consisted of $67.3 \%(\mathrm{~W} / \mathrm{W})$ carbohydrates. The purified polysaccharide also contained $13.8 \%, 37.7 \%$ and $22.6 \%$ of Dglucuronic acid, sulfate and ash, respectively. High-performance anion exchange liquid chromatography (HPAEC) revealed the neutral sugar components of the polysaccharide as Lfucose : D-galactose : D-xylose at a ratio of $27.0: 10.2: 2.5$ (data no shown). The molar ratio of the sugar components and sulfate group are summarized in Table 1. The fucoidan contained high levels of D-galactose and sulfate in addition to L-fucose residues. 
Table 1. Chemical compsition of fucoidan.

\begin{tabular}{cccccc} 
& & & Molar ratio \\
\hline Sample & L-Fucose & D-Galactose & D-Xylose & D-Glucuronic acid & $\mathrm{SO}_{3} \mathrm{Na}$ \\
\hline Fucoidan & 4.0 & 1.5 & 0.2 & 1.0 & 5.0 \\
\hline
\end{tabular}

\section{Effect of fucoidan on U937 cell proliferation}

U937 cells were cultured in RPM1640 medium with fucoidan (50-300 $\mu \mathrm{g} / \mathrm{mL})$ for $48 \mathrm{~h}$. Fucoidan inhibited the proliferation of U937 cells in a dose-dependent manner. About $70 \%$ of viable U937 cells were reduced when $100 \mu \mathrm{g} / \mathrm{mL}$ of fucoidan was added, as shown in Figure 2.

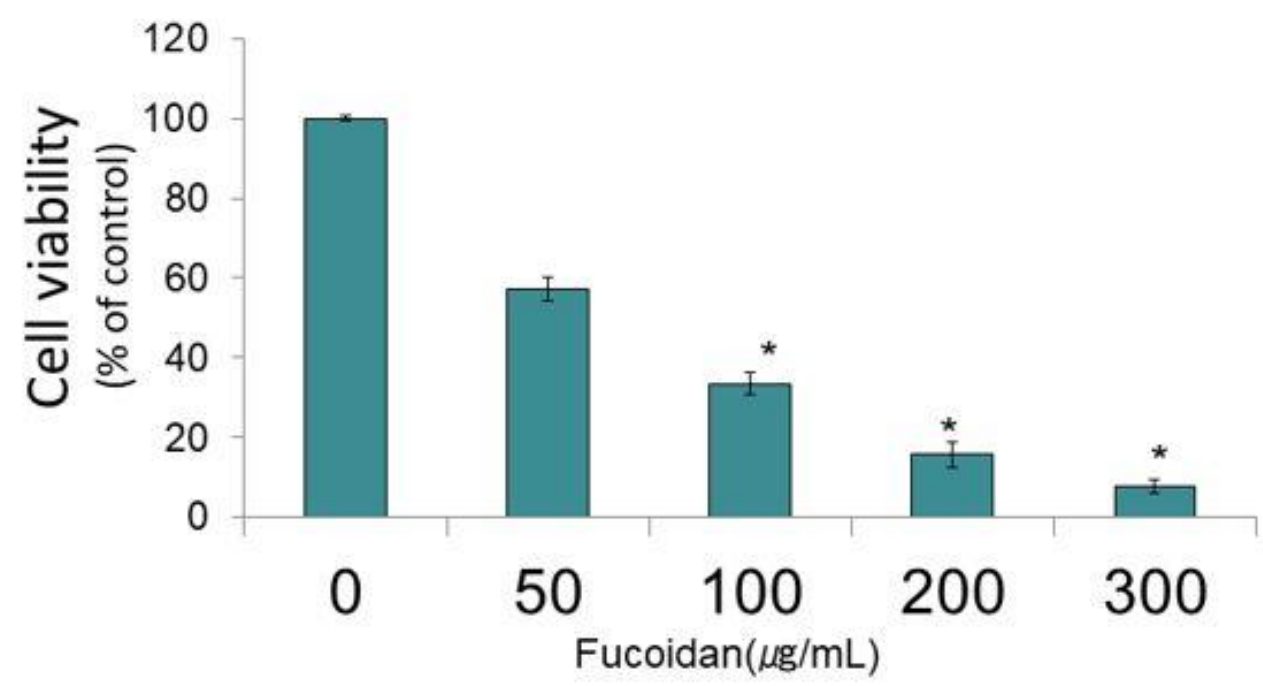

Figure 2. Effect of treatment with fucoidan on cell viability in U937 cells. U937 cells were treated with fucoidan $(50-300 \mu \mathrm{g} / \mathrm{mL})$ for $48 \mathrm{~h}$. Data were means \pm S.E.M. of three independent experiments. Asterisks show statistically significant from the untreated (control) group $\left({ }^{*}: p<0.01\right)$.

Microphotographs of U937 cells after treatment with fucoidan $(100 \mu \mathrm{g} / \mathrm{mL})$ for $30 \mathrm{~h}$ are shown in Figure 3. Arrows indicate the apoptotic bodies and nuclear condensation (original magnification $300 \times)$. The morphological characteristic of cell death, such as cytoplasmic blebbing and segmenting of cell bodies, were observed in U937 cells treated with fucoidan. 


\section{(a) Control}

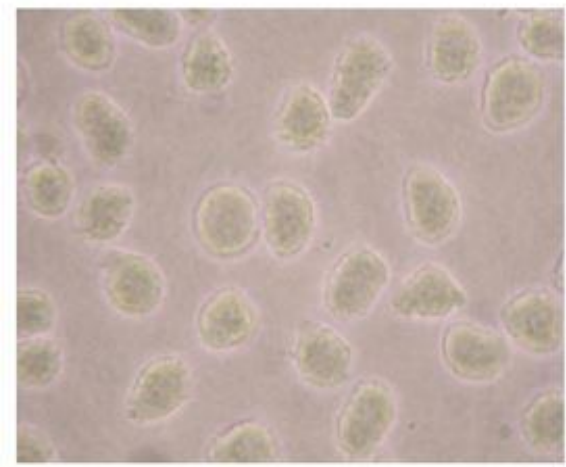

(b) Fucoidan $(100 \mu \mathrm{g} / \mathrm{mL})$

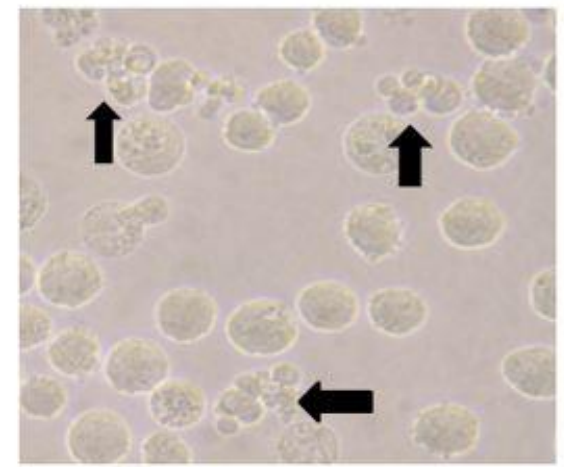

Figure 3. Microscopic appearance of U937 cells treated without (a) or with 100 $\mu \mathrm{g} / \mathrm{mL}$ of fucoidan (b) for $30 \mathrm{~h}$. At the end of each culture period, cells were imaged using a phase contrast microscope and digital camera. Arrows indicate the apoptotic bodies and nuclear condensation.

\section{Induction of apoptosis by fucoidan}

The APOPercentage apoptosis assay is based on the transfer of phosphatidylserine from the inner membrane leaflet to the outer membrane leaflet, which occurs when the cell is undergoing apoptosis. Microphotographs of U937 cells treated with or without fucoidan for $48 \mathrm{~h}$ and then labelled with APOPercentage dye are shown in Figure 4a and 4b. Arrows indicate the apoptotic bodies and nuclear condensation. Many living cells were observed in the absence of fucoidan (Figure 4a). However, pink-staining apoptotic bodies were found in fucoidan-treated cells (Fig.4b).

(a) Without fucoidan

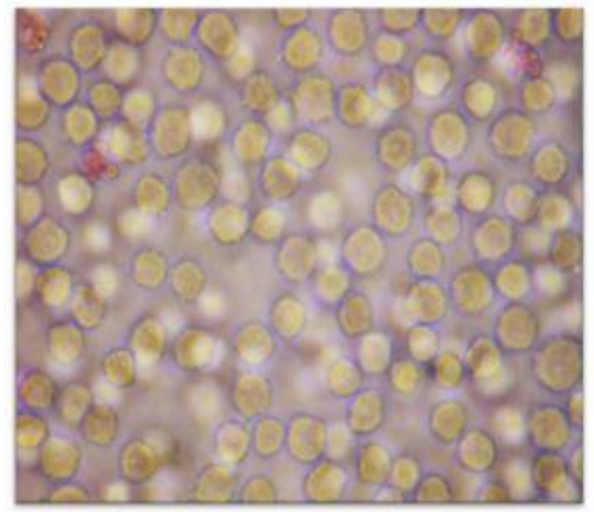

(b) Fucoidan $(100 \mu \mathrm{g} / \mathrm{mL})$

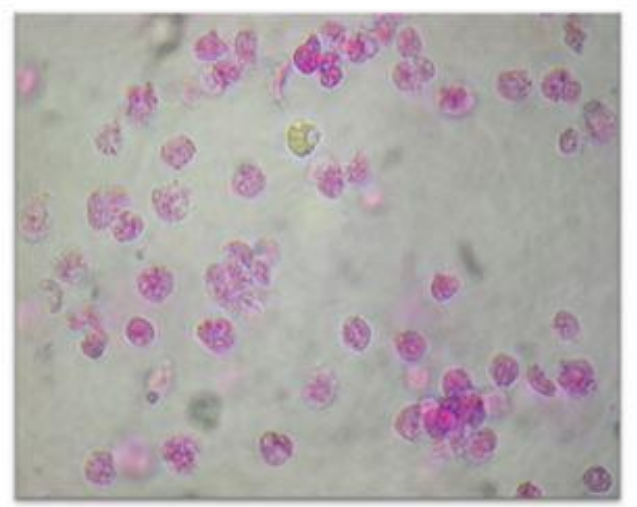

Figure 4. Microphotographs of U937 cells treated without (a) or with100 $\mathrm{Lg} / \mathrm{mL}$ of fucoidan (b) for $30 \mathrm{~h}$ and then labelled with APOPercentage Dye. Apoptotic bodies were stained in pink color. 


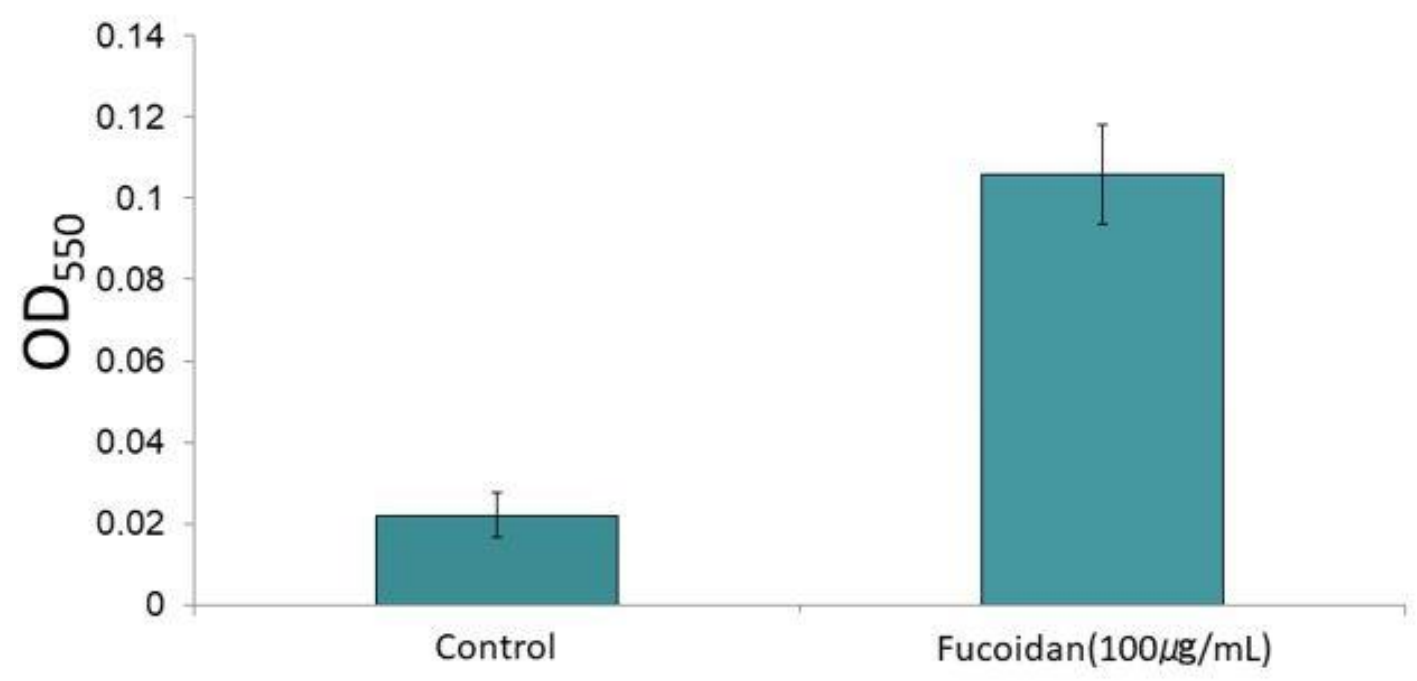

Figure 5. Effect of fucoidan on induction of apoptosis in U937 cells. U937 cells were treated with fucoidan $(100 \mu \mathrm{g} / \mathrm{mL})$ for $30 \mathrm{~h}$. Data were means \pm S.E.M. of three independen $t$ experiments.

The pink-staining cell fragments were collected by centrifugation and lysed by adding cell lysis solution $(0.1 \mathrm{M} \mathrm{NaOH})$. The optical density was measured at $550 \mathrm{~nm}$ in a microplate reader. As shown in Figure 5, apoptosis was induced after treatment with fucoidan $(100 \mu \mathrm{g} / \mathrm{mL})$.

\section{Effect of fucoidan on caspase activity}

Caspases plays a central role in the apoptotic response by degrading cellular substances. Caspase3 is a member of the cysteine-aspartic acid protease family and is activated in the apoptotic cell both by extrinsic (receptor-mediated) and intrinsic (mitochondria-mediated) pathways. Caspase-3 exists as an inactive proenzyme that undergoes proteolytic processing at a conserved aspartic acid residue to produce two small subunits that the active enzymes. The two small enzymes cleave and activate caspase- 7 , and the protein itself is processed the activated by caspase- $8,-9$ and -10 , so it is the predominant caspase in the apoptosis processes [10,12]. The caspase-3 activity in the fucoidan-treated cells was monitored with a colorimetric assay.

The addition of fucoidan 50 to $100 \mu \mathrm{g} / \mathrm{mL}$ increased the caspase- 3 activity in the treated cells with dose-dependent manner. However, no apoptosis induction was observed following the addition of a caspase inhibitor (z-VAD-fmk) which is a cell-permeable pan-caspase inhibitor that irreversibly binds to the catalytic site of caspase protease-3, as shown in Figure 6. 


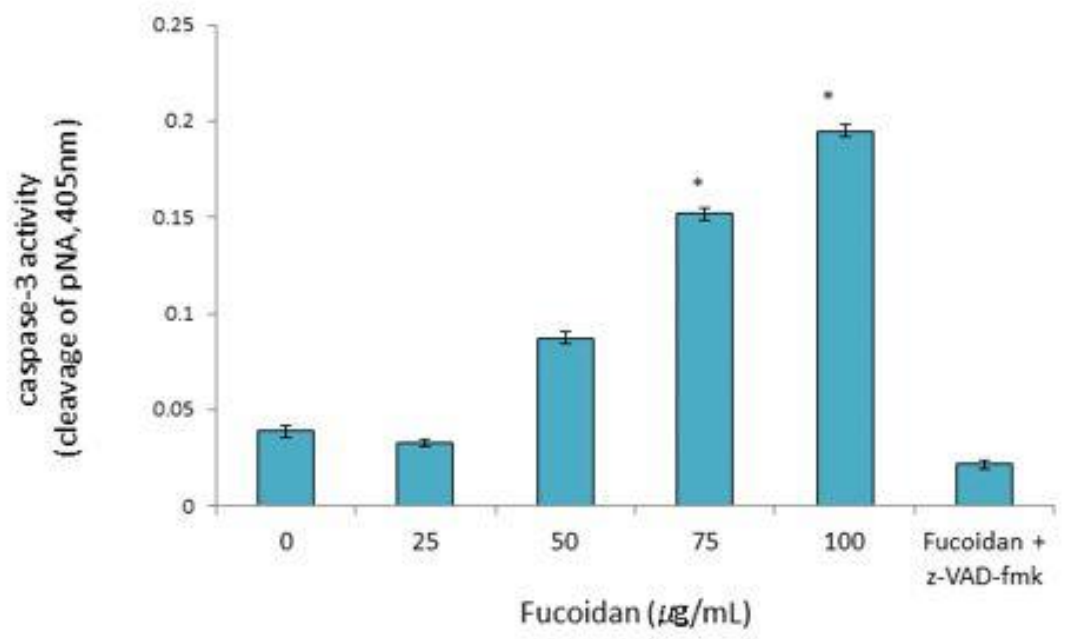

Figure 6. Induction of caspase 3 activity in U937 cells treated with fucoidan (25-100 $\mathrm{gg}$ /mL). Data were means \pm S.E.M. of three independent experiments. Asterisks show statistically significant differences from the untreated(control $) \operatorname{group}\left({ }^{*}: \mathbf{p}<0.01\right)$.

\section{Western blotting analysis}

Caspase-3 activation in U937 cells was examined after treatment with fucoidan by Western blotting analysis (Figure 7). Fucoidan treatment increased the levels of active 17 and $21 \mathrm{kDa}$ caspase-3 in a dose-dependent manner. Concurrently, the procaspase-3 fraction (32 kDa) was decreased with increases in fucoidan concentration. These results indicated that fucoidan addition induced apoptosis by activation of caspase-3. However, apoptosis was not observed to co-existed in the caspase inhibitor (z-VAD-fmk).

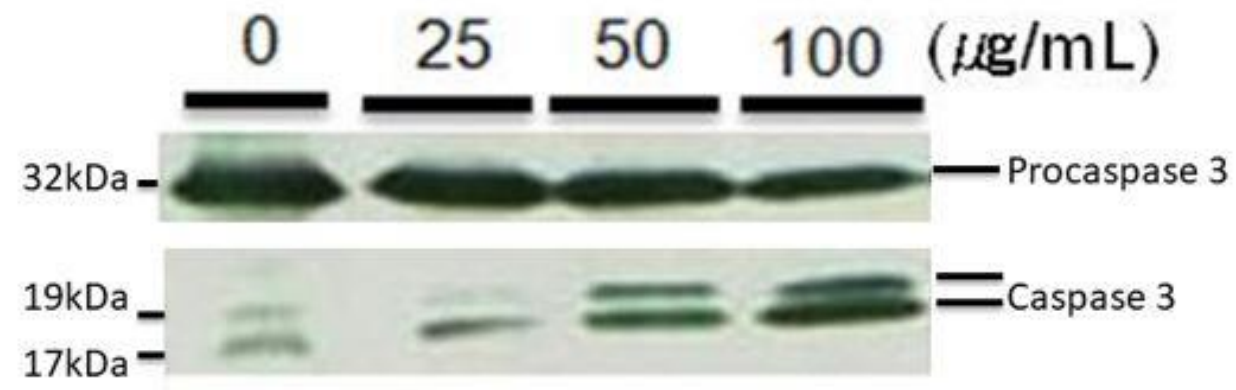

Figure 7. Induction of caspase 3 activity in U937 cells treated with fucoidan $(25-100 \mathrm{Lg} / \mathrm{mL})$. Immunoblot analysis with anti-caspase -3 for $32 \mathrm{kDa}$ and, 19 and $17 \mathrm{kD}$ a subunit. 


\section{DISCUSSION}

Though many studies have been reported on fucoidan from some brown seaweeds which induced apoptosis [9-17], there is no investigation from a kelp, Saccharina longissima, which is an important traditional foodstuff for 300 years in Okinawa, Japan. In this study, we found that the fucoidan isolated from the kelp induced apoptosis in U937 human leukemia cells. The results demonstrated that the fucoidan inhibited cell growth and induced apoptosis in U937 cells, which was indicated by decreasing cell proliferation, increasing fragmentations of death cells and increasing the levels of active 17 and $21 \mathrm{kDa}$ caspase- 3 in a dose-dependent manner. The U937 cell numbers were reduced by about $70 \%$ and pink-stained cell membranes indicated cell debris after apoptosis. Furthermore, the pan-protease inhibitor, z-VAD- fmk, prevented fucoidan-induced apoptosis, suggesting that caspase-dependent apoptotic pathways are involved. After binding fucoidan on the receptor-sites on U937 cells, caspase-8 is activated. Then the intrinsic pathway is initiated by cleavage of procaspase-3 into an active form, which results in DNA fragmentation of nuclear proteins, crosslinking of proteins, and then formation of apoptotic bodies. In humans, 14 caspases have been identified. The caspase family is classified into initiator caspase such as caspase- 8 and -9 and effector one such as caspase-3, -6 and -7 . Initiator caspases are activated by two major pathways, one that is a receptor (extrinsic) pathway and another which is a mitochondrial (intrinsic) pathway. In both pathways, initiator caspase activates effector caspase and activated effector caspase progress into further apoptotic process [12,14]. The fucoidan used in this study [1] substituted with many sulfate groups about $37.7 \%$ at C-4 of 1,3-linked $\alpha$-Lfucopyranosyl residues (Figure 1). As reported previously, the low sulfate content of a fucoidan (13.5\%) isolated from commercially cultured Cladosiphon okamuranus demonstrated weak apoptosis in U937 cells, but increased significantly after oversulfation (32.8\%) [10]. The results suggest that the sulfate groups in the fucoidan molecules are important factors of apoptotic activity. On the other hand, Aisa et al [9] and Yamashita et al [12] reported that fucoidan induced apoptosis by the activation of caspase- 3 and/or caspase -8 . These conclusions suggest that both caspases may also play a dominant role in apoptosis on U937 cells.

One of the authors, MT, has been eating about 15-20 g of boiled Saccharina longissima 10 days per month for 20 years. This eating habits has contributed to the maintenance of strong skin, bones and blood vessels. Indeed, MT looks 10-15 years younger than their actual age and enjoys a healthy life. The kelp, S. longissimi, provides many essential nutrients, in addition to polysaccharides (e.g., fucoidan, alginate and laminaran), including proteins (including amino acids), calcium, magnesium, iron, and iodine [20]. In particular, iodine is essential for proper 
functioning of the thyroid gland, which is required to make the hormones that regulate metabolism in the human body. However, taking too much iodine can also result in hormonal disorder. Accordingly, MT eats boiled kelp, which provides about $70 \%$ iodine removed in separate boiling water pot. This may explain his youthful skin, bones, and blood vessels.

Saccharina longissima is a major traditional food which has been eaten for 300 years in Okinawa, Japan. As for 2009, the Okinawan population had the best health and greatest longevity on the planet. However, present-day Okinawan populations with the greatest longevity are decreasing due to changes in food customs, especially with the decrease in kelp consumption by about 25 percent. Kelp consumption seems to contribute to the health and longevity of human beings, as evidenced by MT's experience. Many kinds of kelps are used as foodstuffs in Eastern Asia (Japan, China, South Korea and Taiwan). However, S. longissima is the only kelp traditionally consumed by the Okinawan population in daily life for 300 years, which has contributed to improving their longevity.

\section{CONCLUSION}

The fucoidan from Saccharina longissima inhibited growth and induced apoptosis in U937 human leukemia cells. The effects mediated by activation of caspases. The results and discussion suggest that the kelp containing this fucoidan may contribute to the observed longevity of the Okinawan population.

List of Abbreviations: DMSO, dimethyl sulfoxide; DTT, dithiothreitol; Ac-DEVD-pNA, Nacetyl-Asp-Glu-Val-Asp-p-Nitroanilide; SDS, sodium dodecyl sulfate.

Competing Interests: The authors declare that they have no competing interests.

Author Contributions: J.S., T.Y. and M.N. experimented and collected data, T.T. designed the experiments, T.K. checked the data, and M.T. created the experiments and wrote the paper.

\section{REFERENCES}

1. Tako M, Takeda S, Teruya T, Tamaki Y: Chemical characteristics of fucoidan isolated from Laminaria angustata var. longissimi. Nippon Shokuhin Kougyou Gakkaishi 2010 57, 495-502. (In Japanese)

2. Nishino T, Ura H, Nagumo T: Relationship between the sulfate content and the 
anticoagulant activity of an $\alpha(1-2)$-fucoidan purified from a commercial fucoidan fraction. Botanica Marina 1999, 38: 187-193.

3. Dimesh S, Menon T, Hanna LE, Suresh Y, Salthuvan M, Manikannan K: In vitro antiHIV activity of fucoidan from Sargassum swartzill. International Biological Macromolecules 2015, 82: 83-88.

4. Li H, Li J, Tang Y, Lin L, Xie Z, Zhou J, et al.: Fucoidan from Fucus vesiculosus suppresses hepatitis B virus replication by enhancing extracellular signal-regulated kinase activation. Virology Journal 2017, 14: 178-185.

5. Itoh H, Noda H, Anno H, Zhang C, Mizuno T: Antitumor activity and immunological properties of marine algal polysaccharide, especially fucoidan, prepared from Sargassum thunbergii of faeophyceae. Anticancer Research, 1993: 13, 2045-2052.

6. Ohnogi H, Naito Y, Higashimura Y, Uno K, Yoshikawa T: Immune efficacy and safety of fucoidan extracted from Gagome Kombu (Kjellmaniella crassifolia ) in healthy Japanese subjects. Japanese Journal of Complementary and Alternative Medicine 2015, 12: 87-93.

7. Stefaniak-Vidorsson NM, Gudjunsdottir M, Marteinsdottir G, Sigurjonsson OF, Kristhergsson K: Evaluation of bioactivity of fucoidan from luminaria with in vitro human cell culture (THP-1). Journal in Health and Disease 2017, 7, 688-701.

8. Atachrazm F, Lowenthal RM, Woods GM, Hollowway AF, Dickinson JL: Fucoidan and cancer: A multifunctional molecule with tumor potential. Marine Drug 2015, 13: 23272346.

9. Shen HY, Li LZ, Xue KC, Hu DO, Gao YJ: Antitumor activity of fucoidan in anaplastic thyroid cancer via apoptosis and anti-angiogenesis. Molecular Medicine Report 2017, 15: $2620-2624$.

10. Aisa Y, Myakawa Y, Nakazato T, Shibata H, Saito K, Ikeda Y, Kizaki M: Fucoidan induces apoptosis of human HS-sultan cells accompanied by activation of caspase- 3 and down-regulation of ERK pathways. American Journal of Hematology 2005, 78: 7-14.

11. Teruya T, Konishi T, Uechi S, Tamaki H, Tako M: Anti-proliferative activity of oversulfated fucoidan from commercially cultured Cladisiphon okamuranus TOKIDA in U937 cells. International Journal of Biological Macromolecules 2007, 41: 221-226. 
12. Hyun JH, Kim SC, Kim MK, Boo HJ, Kwon JM, Koh YS, Hyun JW, et al.: Apoptosis inducing activity of fucoidan in HCT-15 colon carcinoma cells. Biological Pharmacy Bulletin 2009, 32: 1760-1764.

13. Yamashita-Miyamoto Y, Yamasaki M, Tachibana H, Yamada K: Fucoidan induces apoptosis through of caspase-8 on human breast cancer MCF-7 cells. Journal of Agricultural and Food Chemistry 2009, 57: 8677-8682.

14. Kim EJ, Park SY, Lee JY, Hang, J, Park Y: Fucoidan present in brown algae induces apoptosis of human colon cancer cells. BMC Gastroenterology 2010, 10:96: 1-11.

15. Yamasaki Y, Yamasaki M, Tachibana $H$, Yamada K: Important role of $\beta 1$-integrin in fucoidan-induced apoptosis via caspase-8 activation. Bioscience, Biotechnology, and Biochemistry 2012, 76: 1163-1168.

16. Zhang Z, Teruya K, Eto H, Shirahata S: Induction of apoptosis by low-molecular weight fucoidan through calcium- and caspase-dependent mitochondorial pathways MDA-MB231 breast cancer cells. Bioscience, Biotechnology and Biochemistry 2013, 77: 235-242.

17. Park HS, Hwang HJ, Kim GY, Cha HJ, Kim WJ, Kim ND, Choi YH: Induction of apoptosis by fucoidan in human leukemia U-937 cells through activation of MARK and modulation of Bcl-2 family. Marine drugs 2013, 11: 2347-2364.

18. Banafa AM, Rosham S, Liu Y, Zhao S, Yang G, He G, Chen M: Fucoidan induces apoptosis in MDA-234 cells by activating caspase cascade and down-regulating XIAP. Journal of Pharmacy and Biological Science 2014, 9: 59-64.

19. Dubois M, Gilles KA, Hamilton JK, Rebers PA, Smith F: Calorimetric method for determination of sugars and related substances. Analytical Chemistry 1956, 28: 350-356.

20. Bitter B, Mair HM: A modified uronic acid carbazole reaction. Analytical Biochemistry 1962, 208: 101-108.

21. Willcox BJ, Willcox C, Suzuki M: The Okinawa Program- How the world's Longestlived people achieve everlasting health- and how you can too. New York: Three Rivers Press; 2001: 167-170. 